\title{
Sobre mulher e filosofia ou uma canção para Simone de Beauvoir
}

\author{
Izilda Johanson ${ }^{1}$
}

Resumo: Quem frequenta discussões e debates dedicados à filosofia de Simone de Beauvoir sabe que não é incomum surgir em algum momento a inevitável questão sobre essa grande pensadora do século XX ter-se considerado principalmente escritora, mas não filósofa. Nossa proposta é de enfrentar essa questão diretamente como uma questão ou um problema de filosofia, e não um problema de Simone de Beauvoir com a filosofia, como alguns autores e autoras, filósofas feministas inclusive, há algum tempo vêm insistindo em fazer. Entendemos que o engajamento intelectual e feminista de Simone de Beauvoir é não só compatível como necessário à afirmação da autenticidade e originalidade de sua filosofia.

Palavras-chave: Mulher - Filosofia - Filósofa - Interdisciplinaridade - Feminismo

\section{On women and philosophy or a song for Simone de Beauvoir}

\begin{abstract}
Anyone who attends discussions and debates dedicated to the philosophy of Simone de Beauvoir, a great thinker of the 20th century, knows that it is not uncommon that at some point someone raises the inevitable question about her claiming to be herself mainly a writer, but not a philosopher. Our proposal is to face this question directly as a question or a problem of philosophy and not as a Beauvoir's problem with philosophy, as some authors, including feminist philosophers, have been insisting for some time. We understand that Simone de Beauvoir's intellectual and feminist engagement is not only compatible but necessary to affirm the authenticity and originality of her philosophy.
\end{abstract}

Keywords: Woman - Philosophy - Philosopher - Interdisciplinarity - Feminism

\footnotetext{
${ }^{1}$ Professora de Filosofia Contemporânea do Departamento e do Programa de Pós-Graduação em Filosofia na Universidade Federal de São Paulo. Doutora em Filosofia pela Universidade de São Paulo. i.johanson@unifesp.br.
} 
Se você tem uma ideia incrivel, é melhor faz̧er uma canção. Está provado que só é possivel filosofar em alemão.

Caetano Veloso, Lingua

\section{Simone de Beauvoir e sua obra}

Quando se trata de escrever sobre o pensamento e a obra de Simone de Beauvoir, costuma ser inevitável fazer referência a $O$ segundo sexo, seu mais conhecido livro, que se liga à vida e à história do século XX de modo marcante, e adentra de modo agudo nas questões que dizem respeito sobretudo à vida, às condições e à situação da mulher nesse mundo - até hoje - fundamentalmente masculino, feito por homens, para homens e em função dos seus interesses e seus poderes.

O segundo sexo foi publicado integralmente em 1949. Nesse momento, sua repercussão, tanto do ponto de vista do público quanto da crítica, foi principalmente negativa: condenado como obra indecente, de uma mulher pervertida, ninfomaníaca, livro destinado a "ridicularizar o macho francês" e capaz de "provocar o riso das operárias de Billancourt", entre outras avaliações pouco receptivas. Nos anos 60 e 70, com os movimentos estudantis e sociais da França e, sobretudo, nos EUA, O segundo sexo foi trazido de volta à luz, agora de modo predominantemente positivo, sobretudo pelas mãos das feministas daquela que se convencionou chamar de Segunda Onda. Nesse contexto, o livro passa a ser lido e catalogado como obra feminista e, dada a sua anterioridade em relação a abordagens de temas e proposição de teses em questão naquele momento, como uma espécie de precursor da produção feminista a partir de meados do século XX. É bem provável que muitas, senão todas, as feministas dessa época tenham sido leitoras de Simone de Beauvoir. Fosse para prolongar as questões e temas postos pelo segundo sexo, fosse para criticá-los ou mesmo se opor a eles, o livro, como se disse, passou a ser um marco e uma referência teórica fundamental para os estudos feministas e de gênero empreendidos a partir de então ${ }^{3}$.

O mesmo, infelizmente, não se passou na Filosofia. O segundo sexo teve e ainda tem sua importância e seu lugar no campo das ações e reflexões feministas e em meio à sua diversidade de abordagens e áreas de conhecimento. No que diz respeito ao universo da produção filosófica, contudo, esse livro raramente veio a ser considerado sequer relevante. Em princípio, - acostumamo-nos a ouvir dos filósofos ditos sérios - se há algum interesse, este talvez se encontre no campo da sociologia, da literatura, da história talvez, certamente

\footnotetext{
2 BEAUVOIR, A força das coisas, p. 149

${ }^{3}$ Não será possível desenvolver aqui, no entanto, também não se pode deixar de mencionar, a complexidade que envolve a questão da recepção inicial de $O$ segundo sexo no contexto estudunidense e que nos leva a destacar, em meio ao "auê" que ele provocou, também uma atitude de silenciamento desta autora - mulher e filósofa -, não só nos meios reacionários e antifeministas, como no das próprias feministas em processo de afirmação teórica e política nos anos 1960-70. Heci Regina Candiani chama atenção para esse ponto. A hipótese do silenciamento de Beauvoir é inicialmente levantada por Margaret Simons em seu artigo "The Silencing of Simone de Beauvoir: Guess What is Missing from The Second Sex" (1983). Nele, Simons aponta detalhadamente a omissão de conceitos, referências, personagens históricas e argumentos de Beauvoir no momento da tradução de Le deuxième sexe para o inglês. A qualidade duvidosa da tradução, os objetivos editoriais, e o contexto político estadunidense em que esse trabalho foi realizado apresentavam todas as condições para sustentar esse processo de omissão e supressão de ideias como condizente com os interesses não apenas do campo intelectual, como também dos campos político e econômico nos Estados Unidos. [...] No caso estadunidense, Beauvoir era essencialmente uma agente estrangeira, marginal em função da língua, das ideias, e sobre cuja obra esse campo não hesitou em exercer uma apropriação claramente interessada, omitindo do texto tudo que não lhe convinha" (CANDIANI, "O que pode ser criticado nas críticas a O segundo Sexo", p. 20).
} 
para as feministas e mulheres em geral, mas não para "a" Filosofia, e como se ser mulher e ser filosofia fossem duas coisas que nada tem a ver uma com a outra.

É verdade que boa parte desse entendimento fora também resultado do empenho da própria Simone de Beauvoir que, reiteradas vezes, alegou não escrever livros de filosofia, considerando-se exclusivamente escritora. E, de fato, ela foi escritora. A maior parte de sua produção diz respeito a obras literárias (romances, memórias, dramaturgia e produção epistolar). Algumas delas, inclusive, livros premiados, como no caso de Os mandarins, romance pelo qual recebeu o prestigiado prêmio francês de literatura, o Goncourt, em 1954. A questão, no entanto, é que, ao mesmo tempo em que Beauvoir se assumia escritora, negava também o seu lugar de filósofa. Não foram poucas as vezes em que ela não só dizia não ser filósofa e sim escritora que escrevia eventualmente ensaios teóricos, como afirmava que essa produção teórica era inteiramente constituída a partir da obra de outro filósofo: seu companheiro intelectual e de vida, Jean-Paul Sartre. Há entrevistas de Beauvoir ${ }^{4}$, publicadas por escrito e também em vídeo de programas de televisão, em que ela chega mesmo a dizer que, no entender dela, ela era "discípula de Sartre”. Esse acabou se tornando uma espécie de mote seguido à risca por muitos comentadores e estudiosos da obra de Beauvoir, que mantinham a orientação de ler e considerar a sua produção teórica como se esta fosse, de fato, desprovida de originalidade; como se ela fosse apenas uma espécie de apêndice ou satélite que gravitaria em torno da obra de, este sim, considerado filósofo de verdade, JeanPaul Sartre.

Apenas a partir dos anos 70-80, na França - sobretudo a partir da morte de Beauvoir - e mais fortemente dos anos 90, na Europa e nos EUA - que O segundo sexo passou a ser lido também de outra perspectiva. Como numa espécie de redescobrimento de Simone de Beauvoir, esta passa então a ser lida não somente como escritora, romancista, ativista e teórica do feminismo, mas também como filósofa. O segundo sexo, principalmente, passa a ser lido sob novas perspectivas e em novas chaves que, sob nenhum aspecto ou condição, o subordina à obra de Sartre. A perspectiva biográfica ganha papel tanto mais significativo com a realização do grandioso projeto, capitaneado por Margareth Simons em parceria com a herdeira legal e intelectual de Beauvoir, Sylvie Le Bon de Beauvoir, de publicação do vasto acervo de cartas e correspondências e, principalmente, dos diários da jovem estudante de filosofia na Sorbonne. Ao se juntarem a esta as empreitadas teóricas que se voltam também às análises internas e estruturais de sua obra como um todo, a atuação profissional e política da intelectual engajada Simone de Beauvoir, sua produção vai ganhando novo status, não superior ao anterior mas, seguramente, bem mais condizente com a realidade de ensaísta, de escritora e também de mulher de filosofia que era a sua. De uma filosofia, no mais, produto de um pensamento que visava lidar de modo original com as questões de ordem postas por seu tempo próprio e também pela história mais tradicional e hegemônica da filosofia, que busca dialogar com essa história e, ao mesmo tempo, com aquela produzida também por suas/seus contemporâneas/os, que não deixa de se posicionar politicamente e de intervir, por meio da figura pública de sua autora, nos acontecimentos e demandas políticas de sua época.

${ }^{4}$ BEAUVOIR, SIMONS E TODD, “Two Interviews with Simone De Beauvoir”, pp. 11-27. 


\section{Colocação do problema: a "separação do conhecimento"}

Quando, em 2019, estive em Paraty para participar de sua feira literária anual, tive a felicidade de assistir a uma das mesas de entrevista e de conversa com Grada Kilomba, convidada especial da edição da FLIP daquele ano. Ao ser apresentada, na abertura da entrevista, foi à "pesquisadora, artista, pensadora" que a entrevistadora se referiu, ao que, prontamente, já nos agradecimentos preliminares, Kilomba respondeu preferir ser qualificada, diferente de como o foi, como uma "artista interdisciplinar" ". Em seguida, explorando o tema, explica a diferença, nada insignificante, entre as duas coisas, e o quanto que cada uma delas remete, por sua vez, a realidades e projetos éticos distintos e mesmo opostos.

O que pode haver de significativo nessa distinção entre ser "artista interdisciplinar" e ser "teórica e professora e artista plástica e escritora", declara Kilomba, está diretamente relacionado à questão da segmentação do conhecimento. A diferença está em que a secção e, consequentemente, a atomização dos campos do conhecimento e mesmo, aqui podemos acrescentar, entre os campos do conhecimento e o da ação, costuma estar a serviço de certa causa, em princípio, do ponto de vista ético, não muito afeita aos valores feministas. Refirome à causa de tipo meritocrática tão velha conhecida, que vê como positivo um processo de agregação de valor, no sentido mesmo patrimonial, isto é, que quantifica em termos de valor de propriedade certas capacidades, ações e os resultados delas, isto é, seus produtos. A adição de adjetivos, no caso de uma pessoa, supõe, de saída, a possibilidade destes serem passíveis de hierarquização, portanto, de valoração num sentido vertical, quantitativo: quanto maior a soma, quanto maior a pilha de atributos e qualidade, mas alto se está em relação ao chão, ao ponto zero, do valor zero; quanto mais títulos e qualificações, por exemplo, mais alto se pode estar numa suposta hierarquia profissional, mas também, por extensão, social.

No caso da defesa da interdisciplinaridade, de uma atuação em campos diversos de expressão e ação, todas as habilidades são tomadas num mesmo plano horizontalizado intercomunicável e que, portanto, não elevam a pessoa que as possui acima de qualquer outra, pois não se trata de estabelecer diferenças de grau entre as produções humanas, mas de adentrar no plano das diferenças qualitativas, ou, se se preferir, no campo da pluralidade de qualidades produtivas muitas vezes interseccionáveis.

No meu entender, essa compreensão exposta de maneira tão clara e inequívoca por Grada Kilomba, em Paraty no ano de 2019, nos leva ao âmago de nossa questão aqui sobre a relação entre Simone de Beauvoir e a filosofia, em especial, sua alegada recusa de se considerar filósofa.

Arrisco dizer que a ligação de um acontecimento a outro pode estar no fato de que uma das razões para Beauvoir não considerar sua produção teórica como "de filosofia", pode ter muito a ver com esse modo de compreender seus feitos teóricos e práticos (de pensamento e de ação) muito ao modo como Kilomba descreve o dela própria. O mínimo que se poderia conceder, neste caso, é que os feitos inter e multidisciplinares beauvoirianos parecem bastante incompatíveis com um pensamento erguido nos moldes tradicionais do universalismo e da ontologização sistemática da filosofia hegemônica historicamente

5 KILOMBA, Grada e BORGES, Stephanie - Entrevista Flip - Rádio Batuta. Disponível em https://radiobatuta.com.br/programa/grada-kilomba-e-stephanie-borges/ 
estabelecida até os tempos de hoje. O que significa dizer que, em Beauvoir, dizer-se não filósofa pode significar também posicionar-se do lado da recusa dessa filosofia "de filósofos especialistas", que se vê destacada dos demais saberes, se pretende no mais das vezes autossuficiente em meio a práticas e modos de conhecer diversos, e produz inevitavelmente ordens hierarquizadas e hierarquizantes, as quais, na prática, funcionam melhor como meio de manutenção das normas e dos poderes vigentes, do que de libertação, no sentido do engajamento num projeto fundamentalmente ético e explicitamente comprometido com propósitos emancipatórios e libertários da vida humana.

O caso não somente de Simone de Beauvoir, mas das mulheres na filosofia e para a filosofia, é esclarecedor quanto a esse ponto. Ao longo da história consagrada no meio em que aqui no Brasil fomos todas formadas - ou seja, a história de uma filosofia hegemonicamente europeia e eurocêntrica, masculina e não raro masculinista, branca e porta vOZ da branquitude - o que se constata é que em boa parte das filosofias dos principais e mais canônicos filósofos, a mulher costuma ocupar um posto de inferioridade em relação aos indivíduos do sexo masculino na escala que qualifica "a humanidade", e os argumentos e explicações para isso, no mais das vezes, costumam revelar o lado mais criativo de certa imaginação filosófica - em hipótese alguma do pretendido logos filosófico - ou, nos termos de Michèle Le Doeuff, "o segredo de Polichinelo: a liberdade do imaginário face ao real"'. Ora, não por acaso ou coincidência, é o caso das mulheres e o seu viver no mundo concreto (e não no imaginário, mítico), o que inclui, evidentemente, o mundo da filosofia, que está no coração da obra e do projeto intelectual e de vida - um projeto ético, na verdade - de Simone de Beauvoir.

Este ponto nos leva, assim, à questão central deste artigo, que é a da relação entre mulher e filosofia, ou, mais precisamente, sobre o lugar e o papel da mulher na filosofia e em sua história, a partir do caso Simone de Beauvoir.

\section{A relação da filosofia com Simone de Beauvoir}

Muitas estudiosas da obra de Beauvoir lidaram com essa questão. Uma delas foi Toril Moi. Num de seus trabalhos bastante conhecido ${ }^{7}$, esta autora empenha-se em decifrar o enigma da relação de Beauvoir com a filosofia, ou melhor, a negação da existência de uma filosofia por parte dela, tomando por referência a relação de Simone com Jean-Paul. Na verdade, transforma em representativo dessa relação um único episódio da vida de ambos: o famoso, exposto no segundo volume de suas memórias, em que Simone de Beauvoir narra a conversa que teve com Sartre nos Jardins do Luxemburgo, em 1929, em que ambos tentam elaborar sistemas filosóficos, e em seguida Beauvoir logo desiste de sua elaboração, rendendo-se aos argumentos de Sartre. Para Toril Moi, esse acontecimento é representativo não apenas de uma situação pontual na vida de uma jovem brilhante de vinte e um anos, apaixonada, no início de uma promissora trajetória profissional e de vida, abrindo-se para o mundo, mas, muito mais que isto, considera-o símbolo da subordinação intelectual e afetiva

\footnotetext{
${ }^{6}$ LE DOEUFF, L'Imaginaire philosophique, p. 134.
}

${ }^{7} \mathrm{Cf}$. MOI, The Making of an Intellectual Woman. 
de Simone de Beauvoir à Sartre; prova da existência factual de um "segundo sexo" especialmente singular?

Dentre as autoras dedicadas ao estudo e à promoção da obra de Simone de Beauvoir, faço especial menção a Margaret Simons, que talvez tenha sido aquela que mais retoma, há décadas e reiteradamente, esse tema da recusa da autora de $O$ segundo sexo reconhecer-se filósofa. Algumas vezes ${ }^{8}$ Simons parece determinada a buscar nas palavras da própria Beauvoir a afirmação de sua autonomia filosófica. Entrevistando-a diversas vezes, buscou retirar dela o reconhecimento de que era, de fato, e como tantas de nós mulheres filósofas desejávamos tanto ouvir, uma filósofa autêntica. Obtendo sempre o mesmo tipo de resposta de Simone de Beauvoir - a de que ela, afinal, não se considerava filósofa e, pior (no sentido da expectativa da entrevistadora), que reconhecia em Sartre essa condição e, por isso, o seguia - Simons formula sua conclusão, atribuindo à própria Simone de Beauvoir a responsabilidade por essa espécie de mitologia criada em torno do relacionamento dela com Sartre, e de sua pouca relevância em termos de história da filosofia. Em outro trabalho', Simons continua a atribuir o apagamento de aspectos cruciais do pensamento beauvoiriano, em parte, à própria Beauvoir, mas desta vez, procura ir para além dos aspectos de caráter psicológicos e pessoais, atribuindo essa escolha beauvoiriana ora à autopercepção de que seus escritos não configuravam um sistema filosófico, ora ao desejo de proteger Sartre e reafirmar sua importância no pensamento francês, ora, e concomitantemente, à intenção de proteger o próprio pensamento, já que seria mais fácil para leitores e críticos do contexto francês do pós-guerra admitirem que aquelas ideias eram produto de um pensamento masculino do que feminino $^{10}$. Mais recentemente ${ }^{11}$, Margaret Simons volta à carga. Desta vez, sua análise da questão aponta para a possibilidade de Beauvoir, ao escrever suas memórias, ter aberto mão da defesa de uma filosofia (a sua própria) em favor do engajamento político, incluindo o mais propriamente feminista. O que me parece muito instigante é a questão que decorre desse entendimento, e que diz respeito à por que o engajamento (político) feminista seria incompatível com o desenvolvimento ou o aprofundamento de uma filosofia própria ${ }^{12}$.

Aqui começo a tecer algumas considerações a respeito da questão que vou enunciar como sendo menos da relação entre Beauvoir e a filosofia, do que da filosofia mais historicamente consagrada com Simone de Beauvoir. E a insistência, quase obsessão, de certas estudiosas da obra desta com a questão de Beauvoir não se reconhecer filósofa, me leva à minha, talvez, principal consideração.

Em primeiro lugar, gostaria de destacar o excelente estudo de Heci Regina Candiani, cuja abordagem aguda e esclarecedora, e com a qual coloco-me em total acordo, questiona a pertinência e a relevância dessa questão. Concordo com estudiosas como Candiani ${ }^{13}$ que alegam que a insistência nessa questão pode ter algo de quase desrespeitoso em relação à

\footnotetext{
8 SIMONS, "Beauvoir and the Second Sex: Feminism, Race, and the Origins of Existentialism".

9 SIMONS, "Confronting an impasse: reflections on the past and future of Beauvoir scholarship".

${ }^{10}$ SIMONS, "Confronting an impasse: reflections on the past and future of Beauvoir scholarship", pp. 910913.

${ }^{11}$ Cf. SIMONS, Beauvoir's Ironic Sacrifice; or Why Philosophy Is Missing from her Memoirs.

12 "The possibility that Beauvoir's feminist political commitment led her to erase philosophy from her memoirs is suggested by her 1954 novel, The Mandarins. A main character in the novel, Robert Dubreuilh, decides to abandon his memoirs because of politics: 'There are too many weapons in those memoirs that can be used against me.' [...] 'Now that I'm back in politics I have a lot of enemies". (SIMONS, Beauvoir's Ironic Sacrifice; or Why Philosophy Is Missing from her Memoirs).

${ }^{13}$ CANDIANI, "A tessitura da situação: a trama das opressões na obra de Simone de Beauvoir".
} 
própria Simone de Beauvoir. A meu ver, se ela não se considerou filósofa, não é certamente a questão que mais importa. Por outro lado, ela também não é de toda sem sentido. Ela apenas importa e, em particular, a nós mulheres e filósofas, a meu ver, na medida em que, muito provavelmente, conhecendo a filosofia por dentro como conhecemos, temos todo o direito - e acho que o dever também - de suspeitar de que essa recusa de admitir Simone de Beauvoir na Filosofia possa ter alguma coisa a ver com a questão geral (e que, portanto, diz respeito não apenas a Simone de Beauvoir, mas a todas nós), que é a do lugar e do papel da mulher na filosofia, e a da relação entre mulher e filosofia, a qual, tomada do ponto de vista histórico, podemos dizer que sempre foi difícil, dolorosa e muito problemática. Dito de modo direto, um modo por meio do qual se pratica fortemente também a opressão de gênero.

Assim, entendo que podemos aceitar as considerações de ordem estritamente pessoais e - por que não? - idiossincráticas da nossa autora como resposta, sem problema nenhum: ela deve ter lá seus motivos para essa recusa, sejam estes de ordem pessoal ou política, e o porquê disso não é lá muito da nossa conta. A questão, contudo, que me parece mais relevante e mesmo essencial - e desta, sim, penso que não podemos nem devemos nos esquivar ou ignorar, mas enfrentá-la com determinação e coragem - é essa de por que, afinal, no campo filosófico e da produção de conhecimento em geral, se aceitou tão fácil e prontamente, durante tanto tempo, a alegação de que Beauvoir não é filósofa e, desse modo, desconsiderar a sua participação e contribuição real e concreta à história da filosofia.

Isto importa, a meu ver, porque essa concordância com a própria Beauvoir nesse ponto (e, em relação àqueles que a desconsideram, curiosamente nesse ponto apenas), parece soar, em princípio, quase como álibi para o que, na verdade, é uma denegação: como se se dissesse "não sou eu (indivíduo qualquer que se pronuncie sobre a filosofia e o feminismo de modo geral, feminista ou antifeminista), não sou eu que digo que ela não é filósofa, ela mesma é que diz!". Essa espécie de "lavo minhas mãos" é que me parece definitivamente relevante, e é a resposta à questão desse por que se aceita tão facilmente a alegação de Beauvoir de que não era filósofa que eu entendo que nós - feministas, filósofas e não filósofas, em todo caso comprometidas com o pensamento, a obra de Simone Beauvoir e seu legado - devemos a ela, Simone de Beauvoir, e a nós todas, mulheres, também.

Essa resposta começa, a meu ver, com uma consideração muito elementar: o fato de Beauvoir não se considerar filósofa não a retira automaticamente da história da filosofia! E se isto se aplica a tantos, senão todos os filósofos, por que não se aplicaria também a Simone de Beauvoir?

Foucault, por exemplo, também dizia que não era filósofo ${ }^{14}$, e até se referia a estes de modo bem irônico e às vezes sarcástico ${ }^{15}$; nem por isso deixamos de estudar a sua obra na filosofia, nem de considerá-la obra de um filósofo (e a despeito de ser ela tão decisiva, profunda e rica e, por isso, estudada em outras disciplinas, as mais diversas, e ser abordada das mais variadas perspectivas, isto é, não necessariamente filosóficas). Do mesmo modo, o

\footnotetext{
14 "Doit-on vous appeler philosophe? Pas non plus. Ce que je fais n'est aucunement une philosophie. Ce n'est pas non plus une science à laquelle on pourrait demander les justifications ou les démonstrations qu'on est en droit de demander à une science". (Entretiens de Roger-Pol Droit avec Michel Foucault au mois de juin 1975, Le Point $01 / 07 / 04$ - No 1659 p. 82)

15 “(...) je ne suis pas philosophe, je ne suis pas historien, je ne suis pas structuraliste. L'une des identifications positives: je suis journaliste” (FOUCAULT, Michel. Entretien avec F. EWALD. Apud KASULA, Florent Kambasu, p. 20).
} 
que deveria impedir que Simone de Beauvoir entrasse para a história da filosofia seria a irrelevância ou incapacidade de sua obra: ora, mas isto é precisamente o que não se pode afirmar a respeito dela e de sua obra, que sejam incapazes, pobres, ou irrelevantes! Como sabemos muito bem, Beauvoir não é absolutamente nenhuma incompetente em filosofia, como talvez alguns tantos antifeministas e conservadores historiadores da filosofia gostariam de poder afirmar tendo razão (pois que, sem razão, o afirmam ainda hoje e sem nenhum constrangimento ou pudor); e o fato de toda a sua produção despertar o interesse de estudiosas e estudiosos, pessoas de pensamento e de ação, nos mais diversos e variados campos do saber e do conhecimento, também não anula o potencial crítico e inovador de sua filosofia; ao contrário, o confirma ainda mais. Se lida e estudada de uma perspectiva honesta, competente e, principalmente, não preconceituosa (ou seja, livre de machismos, sexismos, misoginia), a obra de Simone de Beauvoir se mostrará não só original como marcante também para a filosofia do século XX, para as ciências sociais e humanas, e para a história do pensamento de modo geral.

Assim, a incapacidade, fruto de má-fé ou da pura má vontade mesmo, em reconhecer que uma mulher seja capaz de tal façanha em filosofia é que é, portanto, a questão que, no meu entender, interessa pôr em relevo. E enfrentar aberta e honestamente.

Esse reconhecimento de que as mulheres existem na filosofia como filósofas autênticas e legítimas tem sido desde os primórdios da filosofia algo sem dúvida muito difícil de acontecer, e não fosse pelo trabalho das feministas de mostrar a pertinência e a relevância das obras de mulheres como Simone de Beauvoir que, no entanto, são reiteradamente apagadas da história da filosofia, eu diria que é impossível de acontecer, dado ser esta o lugar do sexismo, do falocentrismo, da falocracia e da misoginia "por excelência". E é por isso também que, a meu ver, o reconhecimento da produção de Beauvoir como filosófica é importante não só para as filósofas, mas para todas as mulheres, dado que, historicamente, a elas nunca costumam ser associados grandes feitos e grande contribuições humanas. A produção das mulheres inexiste nessa história edificada pelo masculinismo, principalmente quando o que elas fazem extrapola o campo social e historicamente reservado a elas - basicamente, privado, doméstico (de reprodutora, cuidadora, etc.) - e alcança aquele outro, que os próprios homens reservam exclusivamente para si, que é o da ação no espaço público, das ideias também, da produção de conhecimento e do pensamento ${ }^{16}$.

Além disso, me parece que Beauvoir nunca precisou deixar de ser filósofa, nem de fazer filosofia, para ser, como de fato foi, escritora de literatura (romanesca, epistolar, memorialista, etc.), ativista, intelectual feminista e tudo o mais que sabemos que ela foi. A bem dizer, esse modo de Simone de Beauvoir ser o que foi e da maneira como foi está em perfeita sintonia com o modo de ser filósofo da geração dela, incluindo Sartre, mas não apenas ele. ${ }^{17}$ Se prestarmos atenção ao quadro de fundadores e de colaboradores da Les temps

\footnotetext{
${ }^{16}$ Neste sentido, não posso deixar de mencionar o quanto é aguda e precisa a proposição da Michèle Le Doeuff de colocar "a escolha de Hipárquia" no centro da discussão da constituição de uma história da filosofia e mesmo de toda e qualquer questão filosófica que se pretenda relevante em filosofia (ver LE DOEUFF, L'Imaginaire philosophique).

17 Podemos mencionar várias/os autora/es de filosofia (até mesmo algumas/uns que não chegaram a ser tão mundialmente conhecidas/os como Sartre, inclusive porque viveram muito menos, morreram jovens devido, justamente, a esse engajamento na vida que se fazia não apenas por meio do pensamento, mas também da ação) como Simone Weil, Paul Nizan e Georges Politzer; ou mesmo autores cuja produção principal liga-se a outras áreas, como é o caso de Camus: obras primordialmente associadas à literatura, mas estudadas sem nenhuma dificuldade na filosofia, como obra de filósofo também.
} 
modernes $^{18}$, por exemplo, veremos sem dificuldade que o perfil padrão do intelectual daquele tempo na França não foge muito do perfil da intelectual Simone de Beauvoir: todos ali eram, ao mesmo tempo, filósofos (geralmente fizeram uma graduação, defenderam tese em filosofia e escreviam "ensaios teóricos", como dizia Beauvoir), jornalistas, documentaristas, dramaturgos, poetas, etc. O que torna Beauvoir excepcional em comparação a esses todos é justamente o fato dela produzir obras (de filosofia, de literatura, etc.) e se engajar na ação de uma perspectiva feminista. Nisto ela foi singular, realizou mais ou menos tanto quanto seus contemporâneos do gênero masculino e foi além, no sentido da criação de algo mais original, especialmente valioso e do qual nenhum deles fora capaz: o feminismo responsável por integrar de modo indelével também mulher e filosofia.

Tomada de uma perspectiva histórica e contextual da filosofia na França em meados do século XX, veremos que a própria concepção de filosofia existencialista ${ }^{19}$ compreendia de certo modo a recusa da filosofia. Melhor dizendo, a recusa de certas filosofias: de modo geral, a metafísica, considerada conservadora e reacionária, e sua contrapartida positivista, antimetafísica, mas não menos antirrevolucionária, ambas produzidas sobretudo no século XIX e virada para o $\mathrm{XX}^{20}$. De modo que a exigência de uma nova filosofia exigia também, e principalmente, a transformação desse indivíduo filósofo num indivíduo engajado nas questões e problemas de seu tempo, os quais, por natureza, extrapolariam o campo fechado da história da filosofia em sentido estrito: indivíduos que produziriam uma filosofia enraizada, nos termos de Georges Politzer, na concretude da vida, no indivíduo concreto e em seus problemas concretos, isto é, dotados de história e lastro social. Ser filósofo, para essa geração, deveria ser algo muito diferente de um metafísico de gabinete ocupado exclusivamente com questões abstratas. Assim como Simone de Beauvoir, filósofas e filósofos de sua geração recusavam e negavam a filosofia, mas em termos bastante precisos: em proveito da criação de um modo diferente de fazer filosofia ${ }^{21}$. Penso que seja principalmente isto que, no mais, fez destas/es filósofas/os autênticas/os - Beauvoir incluída - filósofas/os, no sentido forte do termo: legítimas/os pensadora/es vinculadas/os a uma história da filosofia e, ao mesmo tempo, fortemente comprometidas/os com as questões, os problemas concretos e suas situações.

Trago, por fim, Heci Candiani, mais uma vez, para concordar também no que diz respeito à necessidade de reconhecer que a obra beauvoiriana está inscrita no tempo e, de fato, acolhida em nossa contemporaneidade; mas que se encontra também inserida no contexto de relações complexas - por vezes antifeministas - do campo intelectual, o que a impede muitas vezes de ser inserida num quadro de reconhecimento tradicional:

\footnotetext{
${ }^{18}$ Dentre os quais, como se sabe, encontra-se a própria Simone de Beauvoir.

19 Aqui é preciso destacar que se Simone de Beauvoir costumava recusar a designação de filósofa, o mesmo não acontece em relação à designação existencialista. Simone de Beauvoir não apenas reconhecia a si mesma como uma existencialista, como foi uma das intelectuais que mais contribuiu para a constituir e consolidar o existencialismo como modo de afirmação de um projeto de conhecimento, de pensamento e de ação na França do pós-guerra.

${ }^{20}$ Para destacar dois polos mais expressivos desse eixo, podemos mencionar o espiritualismo, de um lado, e o cientificismo positivista de outro.

${ }^{21}$ Canguilhem, por exemplo, para mencionar um autor francês renomado dessa mesma geração, diz na célebre Introdução de $O$ normal e o patológico, de 1941, que à filosofia interessava toda matéria estrangeira, ou melhor, que apenas poderia interessar à filosofia uma matéria que fosse estrangeira. E assim foi que se dirigiu aos "problemas concretos" da medicina. Quem ousaria dizer que Georges Canguilhem fora médico, mas não filósofo?
} 
Nessa contextualização, é possível perceber que seus conceitos [da filosofia de Simone de Beauvoir] principais ficaram encobertos - e aqui posso mencionar, principalmente, a meu ver, os conceitos de ambiguidade e de situação - e esse encobrimento está certamente relacionado ao fato de que as reações críticas ao trabalho de Beauvoir ao longo de décadas estiveram marcadas pelo fato de que a questão de gênero - especificamente a desvalorização da mulher intelectual - atravessa a recepção das obras. $\mathrm{O}$ campo intelectual é também marcado por resistências de gênero. Se o campo intelectual resiste aos estudos que se debruçam sobre as mulheres (como a própria Beauvoir destaca na introdução de O segundo sexo), o caso de Beauvoir é bastante emblemático por colocar a nu outras resistências que se produzem e se reproduzem também no interior dos estudos feministas e de gênero. No jogo de forças do campo intelectual, silenciar Beauvoir era relativamente necessário talvez para manter o equilibrio já preestabelecido das hegemonias anglo-americana, masculina, pós-estruturalista e tantas outras..$^{22}$

A meu ver, dentre as/os intelectuais da geração de Simone de Beauvoir que sobreviveram à Segunda Guerra, ela foi (penso também em Simone Weil, cujo engajamento na ação foi radical) das que levou mais a sério o propósito de produzir uma filosofia enraizada na concretude da vida humana. A questão, por outro lado, é que essa filosofia aguda da vida concreta não deixa de ser, no limite, uma antifilosofia. Assim, penso que nunca se deve deixar de considerar o quanto a afirmação de que Sartre era o filosofo do casal não deixa de ser também a afirmação de que o que Beauvoir escreveu foi, consciente e deliberadamente, uma antifilosofia, no sentido de uma produção altamente crítica e revolucionária (inclusive em relação à de Sartre), um pensamento infinitamente mais comprometido com a vida que se vive do que com os conceitos, sistemas e abstrações engrandecedoras de mentes e espíritos.

Uma filosofia mais horizontalmente multidisciplinar, que não se reduz certamente ao teórico, mas inclui a produção literária, memorialista, o engajamento político, os manifestos, as produções e sustentações de livros e periódicos, dentre outras das mais diversas; uma filosofia que não ontologiza, nem universaliza, consequentemente, não hierarquiza seres e saberes; uma filosofia, enfim, muito mais comprometida com uma liberdade, entendida como libertação em relação às opressões de toda sorte, do que com a manutenção da ordem, principalmente aquela que favorece e reitera as tramas de poder.

Neste sentido, abrir o campo da história e da história da filosofia para esse tipo de reconhecimento talvez tenha mesmo que ser uma tarefa de todas nós, mulheres de filosofia que vieram depois dela. Nós que aqui estamos, no presente e construindo algum futuro, que não desejamos muito do que tem sido até agora e desejamos muito do que não duvidamos de que precisa vir a ser. Nós que nos empenhamos em seguir adiante e para onde queremos que a filosofia que praticamos - esta canção! - se dirija.

22 CANDIANI, “A tessitura da situação: a trama das opressões na obra de Simone de Beauvoir”, p. 77. 


\section{Referências bibliográficas}

BEAUVOIR, Simone. A força das coisas. Rio de Janeiro: Nova Fronteira. 2013.

O segundo sexo. Rio de Janeiro: Nova Fronteira, 2008.

Margaret A. Simons, and Jane Marie Todd. "Two Interviews with Simone De Beauvoir”. In: Hypatia 3, n. 3, pp. 11-27, 1989.

CANDIANI, Heci Regina. A tessitura da situação: a trama das opressões na obra de Simone de Beauvoir. 2018. 1 recurso online (190 p.). Tese (doutorado) - Universidade Estadual de Campinas, Instituto de Filosofia e Ciências Humanas, Campinas, SP.

. "O que pode ser criticado nas críticas a O segundo Sexo". In: Cadernos Pagu, n. 56, 2019.

CHAPERON, Sylvie. "Auê sobre O segundo Sexo”. In: Cadernos Pagu, n. 12, pp. 37-53, 1999.

FOUCAULT, Michel - Entretiens de Roger-Pol Droit avec Michel Foucault au mois de juin 1975, publicada em Le Point 01/07/04 - No 1659 p .82, consulta em 20/02/2020 em http://www.ipt.univ-paris8.fr/hist/documents/foucault.entretien1975.fr.html

KASULA, Florent Kambasu. Le Pouvoir chez. Michel Foucault: Une épistémologie politique. Paris: Mon Petit Editeur, 2015.

KILOMBA, Grada e BORGES, Stephanie - Entrevista FLIP - Rádio Batuta, rádio de internet do Instituto Moreira Salles, 2019 Disponível em https://radiobatuta.com.br/programa/grada-kilomba-e-stephanie-borges/

LE DOEUFF, Michèle. L'Imaginaire philosophique. Paris: Payot, 1980.

L'Étude et le route. Des femmes, de la philosophie etc. Paris. Seuil. 1989.

MOI, Toril. Simone de Beauvoir: The Making of an Intellectual Woman. Oxford: Oxford University Press, 2008.

SIMONS, Margaret. "Confronting an impasse: reflections on the past and future of Beauvoir scholarship”. In: Hypatia, v. 25, n. 4, pp. 909-926, 2010.

Beauvoir and the Second Sex: Feminism, Race, and the Origins of Existentialism. New York: Rowman \& Littlefield, 1999.

Beauvoir's Ironic Sacrifice; or Why Philosophy Is Missing from her Memoirs. Disponível em: https://www.academia.edu/37013806/Beauvoirs Long_March published title of revise d paper Beauvoirs Ironic Sacrifice. 